Check for updates

Cite this: RSC Adv., 2017, 7, 30439

Received 22nd February 2017

Accepted 26th May 2017

DOI: 10.1039/c7ra02189e

rsc.li/rsc-advances

\section{Synthesis and characteristics of tung oil-based acrylated-alkyd resin modified by isobornyl acrylate}

\begin{abstract}
Xu Xu, (DD *ab Lijing Chen, ${ }^{a}$ Jiawen Guo, ${ }^{a}$ Xiaoqin Cao and Shifa Wang ${ }^{\star a b}$
A tung oil-based acrylated-alkyd resin was synthesized from tung oil, phthalic anhydride, and isobornyl acrylate (IBOA) via an alcoholysis, polyesterification and Diels-Alder reaction with different molar ratios of tung oil and IBOA. The resins were cured at room temperature, and the resulting films were characterized by Fourier transform infrared spectroscopy, nuclear magnetic resonance spectroscopy, atomic force microscopy, thermogravimetric analysis, and differential scanning calorimetry. With the presence of six-membered rings in the polymeric matrix due to the increased content of IBOA, the acrylated-alkyd resins exhibited improved performance characteristics, including mechanical strength, pencil hardness, heat resistance and water resistance.
\end{abstract}

\section{Introduction}

In recent years, increasing attention has been paid to environmentally-friendly materials by considering bio-based products in order to replace petroleum-based products. As one of the most abundant bioresources, vegetable oil-based polymers have been intensively synthesized due to their low cost, environmental friendliness, availability, renewability and possible biodegradability. ${ }^{1-3}$

Drying oils have received more attention compared to other renewable vegetable oils because they can crosslink to a tough, solid film after exposure to air, even at room temperature, through autoxidation without evaporation of water or other solvents. ${ }^{4,5}$ Tung oil (TO) is one of the most abundant drying oils whose major component is a glyceride composed of $\alpha$-eleostearic acid or $(9 Z, 11 E, 13 E)$-octadeca-9,11,13-trienoic acid. ${ }^{6}$ Compared to other unconjugated drying oils, such as soybean and linseed oils, tung oil has a faster drying time, better water resistance, and greater hardness. ${ }^{7-10}$ Tung oil has a highly unsaturated and conjugated triene structure, and hence it can easily be chemically modified in the preparation of alkyd resin, UV-curable acrylate resin, epoxy resin and related polymers to obtain better performance.

Alkyd resins are synthesized by the polycondensation reaction of fatty oils or fatty acids, dibasic acids or acid anhydrides and polyols with hydroxyl functionality greater than two. They usually have several advantages, including biodegradability,

${ }^{a}$ College of Chemical Engineering, Nanjing Forestry University, Nanjing, Jiangsu 210037, People's Republic of China. E-mail: xuxu200121@hotmail.com; Fax: +86 25 85428369; Tel: +862585428369

${ }^{b}$ Jiangsu Key Lab of Biomass-based Green Fuels and Chemicals, Nanjing 210037, People's Republic of China durability, flexibility, good adhesion, and ease of application. ${ }^{\mathbf{1 1 1 , 1 2}}$ However, there are still some drawbacks in traditional alkyd resins, such as bad water resistance, low hardness, and fair thermal stability. ${ }^{\mathbf{1 1 , 1 3 - 1 5}}$ Dibasic acids and acid anhydrides with rigid structures like that of a benzene ring or a fused ring were incorporated into alkyd resins to improve tensile strength, hardness, thermal stability and water resistance, etc. ${ }^{\mathbf{1 6}}$ Furthermore, more effort and attention was paid to tung oil as raw materials to prepare alkyd resins due to its highly unsaturated and conjugated triene structure. ${ }^{17,18}$ Tung oil fatty acids can easily undergo a Diels-Alder reaction with a dienophile because of the conjugated double bonds. The Diels-Alder reaction is one of the most useful reactions applied to the construction of different types of poly adducts. ${ }^{16,17,19}$ It is effective, versatile, and selective, which also suffices most of the requirements for "click" polymer chemistry. The modification of tung oil by the Diels-Alder reaction is useful. It was reported that diacrylate-functionalized tung oil can be prepared via a Diels-Alder reaction with conjugated trienes. ${ }^{20}$ Moreover, Soucek et al. performed a Diels-Alder reaction between acrylate and a conjugated triene to synthesize functionalized tung oil, and its tensile strength, hardness, thermal stability and solvent resistance of alkyd resins were improved. ${ }^{\mathbf{1 7 , 1 9 , 2 1}}$

Isobornyl acrylate (IBOA), which is a commercial turpentinebased acrylate product, can be synthesized from natural renewable turpentine oil. It contains an isobornyl structure, consisting of five and six-ring bicyclic saturated secondary carbon groups with high rigidity and good thermal stability characteristics. Due to its reactive acylate groups, IBOA was used in the preparation of polyacrylate, ${ }^{22}$ polyurethane, ${ }^{23}$ hydrogel, ${ }^{24} \mathrm{UV}$-curable resin, ${ }^{25}$ and so on. The acrylate can react with the $\alpha$-eleosterate fatty acid of tung oil to synthesize functionalized tung oil-based alkyd via a Diels-Alder reaction. ${ }^{17,20}$ In 
this study, a bio-based alkyd resin was synthesized using turpentine-based acrylate and tung oil as raw materials. The tung oil-based alkyd resin was functionalized via a Diels-Alder reaction with IBOA. Its performance characteristics, such as water resistance, pencil hardness and thermal properties were evaluated. These properties were improved by the rigid structure of IBOA.

\section{Experimental}

\subsection{Materials}

Tung oil (saponification value $192 \mathrm{mg} \mathrm{KOH}$ per g, acid value $2.7 \mathrm{mg} \mathrm{KOH}$ per $\mathrm{g}$ ) was obtained from Jinan Liangfeng Chemical Co., Ltd. (China); the fatty acid composition of tung oil is given in Table 1. Phthalic anhydride, xylene, acrylic acid, lithium hydroxide, glycerol, and phenothiazine were purchased from Aladdin Chemical Reagent Co., Ltd. (Shanghai, China). Amberlyst 15 was purchased from Sigma-Aldrich Co., Ltd. (US). Camphene was purchased from Tianchi Chemical Co., Ltd. (Anhui, China). All chemical reagents used were analytical grade.

\subsection{Methods}

2.2.1 Synthesis of IBOA. Herein, $46.82 \mathrm{~g}$ of acrylic acid $(0.65$ $\mathrm{mol})$ and $65.10 \mathrm{~g}$ of camphene $(0.5 \mathrm{~mol})$ were charged into a 250 $\mathrm{mL}$ four-necked round bottom flask equipped with a mechanical stirrer, a reflux condenser and a thermometer.

After the mixture was dissolved at room temperature, $11.19 \mathrm{~g}$ of Amberlyst 15, as the catalyst, and phenothiazine ( $0.03 \mathrm{wt} \%$ of total acrylic acid and camphene), as the polymerization inhibitor, were added. The reaction mixture was heated to $60^{\circ} \mathrm{C}$ for $5 \mathrm{~h}$. The reaction was stopped and the catalyst was recovered by filtration to obtain a reaction crude liquid. Then, IBOA was obtained after unreacted camphene and acrylic acid were distilled off under reduced pressure at $110-120{ }^{\circ} \mathrm{C}$.

2.2.2 Synthesis of tung oil-based acrylated-alkyd resin. Tung oil-based acrylated-alkyd resin was synthesized in three stages comprising alcoholysis (or monoglyceride process), polyesterification and Diels-Alder addition (shown in Scheme 1). Moreover, $19.61 \mathrm{~g}(0.02 \mathrm{~mol})$ of tung oil, $10.13 \mathrm{~g}(0.04$ mol) glycerol and lithium hydroxide $(0.05 \mathrm{wt} \%$ of tung oil) were charged into a $250 \mathrm{~mL}$ four-necked round bottom flask equipped with a mechanical stirrer, reflux condenser, thermometer and nitrogen inlet. The reaction mixture was heated to $220{ }^{\circ} \mathrm{C}$ for $3.5 \mathrm{~h}$ until monoglyceride was formed. ${ }^{26}$ Monoglyceride formation was confirmed by a $95 \%$ ethanol tolerance test. One part of the reaction mixture was mixed with 4 parts of methanol. A completely clear solution of reaction mixture in $95 \%$ ethanol

Table 1 Major fatty acid composition of tung oil

Fatty acid composition $(\%)$

Palmitic acid

Oleic acid

Linoleic acid

Alpha-Eleostearic acid

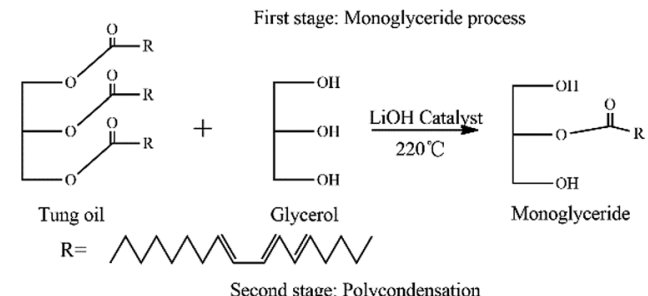

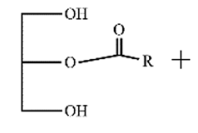

Monoglyceride

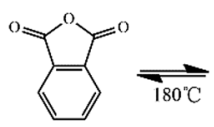

Phthalic anhydride Third stage: D-A addition

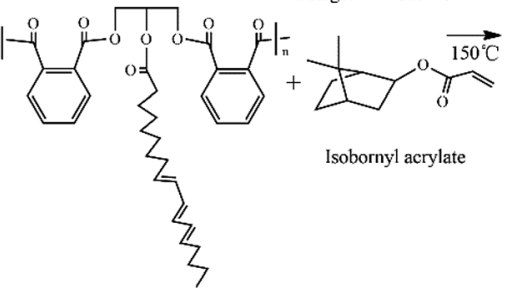

Tung oil based alkyd resin

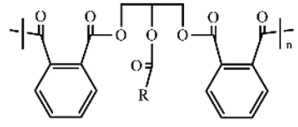

Tung oil based alkyd resin

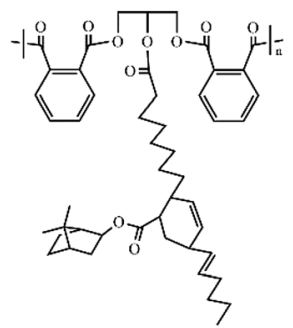

Tung oil based acrylated-alkyd resin
Scheme 1 The synthetic pathway of tung oil-based acrylated-alkyd resin.

indicated the formation of the monoglyceride. Then, the reaction mixture was cooled to $180{ }^{\circ} \mathrm{C}$, and $10 \mathrm{~mL}$ Dean-Stark trap was connected to the flask.

In the second stage, the polycondensation reaction was carried out by adding $19.25 \mathrm{~g}$ phthalic anhydride $(0.13 \mathrm{~mol})$. Water was removed as a by-product by azeotropic distillation using xylene as a solvent. The reaction mixture was heated to $180^{\circ} \mathrm{C}$ for $2.5 \mathrm{~h}$ or until the acid value was less than $30 \mathrm{mg} \mathrm{KOH}$ per $\mathrm{g}$. Then, the reaction mixture was cooled to $120{ }^{\circ} \mathrm{C} ; 10 \mathrm{~mL}$ Dean-Stark trap was removed. ${ }^{2}$

In the third stage, $5,10,15,20,30 \mathrm{wt} \%$ of IBOA (all on the basis of the weight of tung oil) and phenothiazine ( $0.05 \mathrm{wt} \%$ of IBOA) were added to the flask. Then, the mixture was heated to $150{ }^{\circ} \mathrm{C}$ and reacted for $2 \mathrm{~h}$ until the conversion rate of IBOA was more than $95 \%$. Then, the dark yellow transparent tung oilbased acrylated-alkyd resin was obtained.

\subsection{Measurement and characterization}

2.3.1 Physico-chemical properties. The physico-chemical properties of the tung oil-based acrylated-alkyd resin were determined according to the International Union of Pure and Applied Chemistry, Recommended Methods for the Analysis of Alkyd Resins, London $1973 .^{11}$ The viscosity of the acrylatedalkyd resin was measured at $25{ }^{\circ} \mathrm{C}$ using a rotational rheometer (Haake Mars II, Thermo Electron GmbH, Karlsruhe, Germany), equipped with a circulating water bath (DC5, Haake) and a Peltier (TC 81, Haake) temperature-control unit for maintaining the desired temperatures during analysis.

2.3.2 Structure and thermodynamic analysis. A square copper sheet $(5.0 \mathrm{~cm} \times 8.0 \mathrm{~cm} \times 0.2 \mathrm{~mm})$ was used as 
a substrate after it was polished with 800 -grit emery paper. The acrylate-modified tung-oil resin on the copper sheet was prepared by the immersion method and cured at room temperature for $10 \mathrm{~h}$. The thickness of the film was $0.2-0.3 \mathrm{~mm}$. The structures of the cured films were characterized by Fourier transform infrared spectroscopy (FT-IR); this was completed with an FT-IR spectrometer (Nicolet is 10 spectrometer). The spectra were recorded ranging from 4000 to $500 \mathrm{~cm}^{-1}$ at a resolution of $4 \mathrm{~cm}^{-1}$ and averaged over 16 scans per sample. ${ }^{1} \mathrm{H}$ NMR and ${ }^{13} \mathrm{C}$ NMR spectra were recorded at room temperature via Bruker $400 \mathrm{MHz}$ and $100 \mathrm{MHz}$ spectrometers, respectively, and $\mathrm{CDCl}_{3}$ was used as a solvent. Thermal stability was assessed with a TGA-60AH thermogravimetric analyser (Shimadzu, Japan) from $25{ }^{\circ} \mathrm{C}$ to $800{ }^{\circ} \mathrm{C}$ at a constant heating rate of $10{ }^{\circ} \mathrm{C} \mathrm{min}^{-1}$ under nitrogen. Differential scanning calorimetry (DSC) was conducted by DSC-60A (Shimadzu, Japan) under nitrogen atmosphere.

2.3.3 Water absorption testing. The weighed and dried samples were immersed in a bath with deionized water at $25{ }^{\circ} \mathrm{C}$ for $24 \mathrm{~h}$. The samples were removed from distilled water, and the residual water on the surface of the sample films was wiped away. After that, the samples were weighed. The water absorption of the film was calculated as follows:

$$
\text { Water absorption }=\left(W_{1}-W_{0}\right) / W_{0} \times 100 \%
$$

where $W_{0}$ is the initial weight of the sample, and $W_{1}$ is the sample weight after $24 \mathrm{~h}$ of immersion.

\subsubsection{Mechanical properties}

Tensile properties. Tensile properties were measured using an Instron 4201 equipped with a $1 \mathrm{kN}$ electronic load cell according to ASTM D 638-10. The tests were conducted at room temperature at a crosshead speed of $10 \mathrm{~mm} \mathrm{~min}^{-1}$. Five replicates were tested for each sample to obtain an average value. Films on copper sheets were used to test the pencil hardness (ASTM D 3363-74).

Microscopic morphology and roughness. An Atomic Force Microscope (AFM, Anasys Instruments, USA) was used for characterizing the surface morphology and roughness of the sample. All measurements were performed in tapping mode under atmospheric conditions.

\section{Results and discussion}

\subsection{FT-IR spectra analysis of tung oil-based acrylated-alkyd resin}

Fig. 1 illustrates the FTIR spectra of tung oil monoglyceride, alkyd resin and acrylated-alkyd resin, respectively. In the IR spectrum of tung oil monoglyceride, tung oil-based alkyd resin and tung oil-based acrylated-alkyd resin (Fig. 1), the broad single absorption peak at $3461 \mathrm{~cm}^{-1}$ confirmed the presence of an $\mathrm{OH}$ group from the monoglyceride of tung oil. The peak at $3032 \mathrm{~cm}^{-1}$ corresponded to olefinic $\mathrm{C}-\mathrm{H}$ stretching due to the unsaturated fatty acids of tung oil and also corresponded to aromatic $\mathrm{C}-\mathrm{H}$ stretching from the benzene ring in phthalic anhydride, which appeared in all samples, including tung oil monoglyceride, tung oil-based alkyd resin and tung oil-based

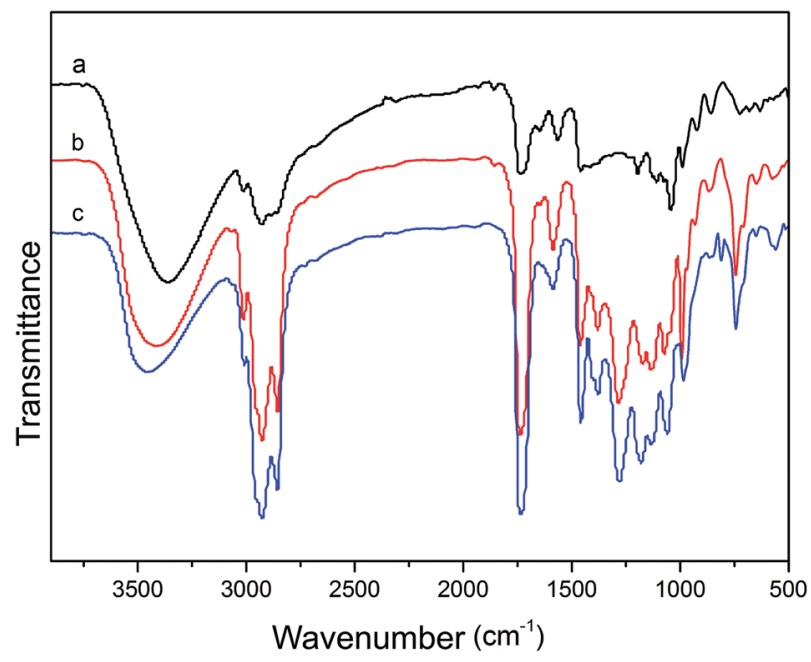

Fig. 1 FT-IR spectra of tung oil monoglyceride. (a) Tung oil-based alkyd resin (b) and tung oil-based acrylated-alkyd resin (c).

acrylated-alkyd resin. The peaks around $2850-2931 \mathrm{~cm}^{-1}$ corresponded to an aliphatic $\mathrm{C}-\mathrm{H}$ stretching band, as shown in Fig. 1. The characteristic peak at $1735 \mathrm{~cm}^{-1}$ was related to $\mathrm{C}=\mathrm{O}$ stretching of ester linkages, which indicates some modification around the carbonyl group of tung oil-based alkyd resin in Fig. $1 \mathrm{~b}$ and $\mathrm{c}$. The aromatic $\mathrm{C}=\mathrm{C}$ stretching frequency from the benzene ring in phthalic anhydride was observed at 1599$1580 \mathrm{~cm}^{-1}$. The peaks around $1279-1059 \mathrm{~cm}^{-1}$ corresponded to C-O-C stretching of ether. Furthermore, the bond at $838 \mathrm{~cm}^{-1}$ in Fig. 1c was a characteristic peak of acrylate; this indicated that the acrylate reacted with the double bonds in tung oil through a Diels-Alder reaction. ${ }^{27}$

\section{2 ${ }^{1} \mathrm{H}$-NMR and ${ }^{13} \mathrm{C}-\mathrm{NMR}$ spectra analysis of tung oil-based acrylated-alkyd resin}

Fig. 2 displays the ${ }^{1} \mathrm{H}-\mathrm{NMR}$ and ${ }^{13} \mathrm{C}$-NMR spectra of tung oilbased alkyd resins. The occurrence of the Diels-Alder reaction was confirmed by the appearance of new peaks at 5.60$6.00 \mathrm{ppm}$ in Fig. 2a, which was attributed to the resonance of $\mathrm{CH}_{2}=\mathrm{CH}_{2}$ protons from cyclohexene, and the methylene protons adjacent to hydroxyls in glycerol are seen at 4.27$4.47 \mathrm{ppm}$. The peak resonances at 6.20-6.70 ppm were attributed to the aromatic ring protons from the phthalic anhydride, and the peak at $4.60 \mathrm{ppm}$ corresponded to protons of the more electron withdrawing ester group from IBOA. ${ }^{22}$ In the ${ }^{13} \mathrm{C}-\mathrm{NMR}$ spectra of Fig. 2b, it was observed that the appearance of peaks at 63.70-69.00 corresponded to the methylene of the glyceride. A pronounced difference between materials can be seen by the appearance of new peaks at $130.00-131.30 \mathrm{ppm}$ due to the Diels-Alder reaction. Hence, from the ${ }^{1} \mathrm{H}-\mathrm{NMR}$ and ${ }^{13} \mathrm{C}-\mathrm{NMR}$ results, it can be concluded that tung oil-based acrylatedalkyd resin was successfully prepared, which is also consistent with the above FT-IR results.

\subsection{The morphology of the films}

To study the effect of IBOA on the morphology of alkyd resin, the as-prepared acrylated-alkyd resin samples were 

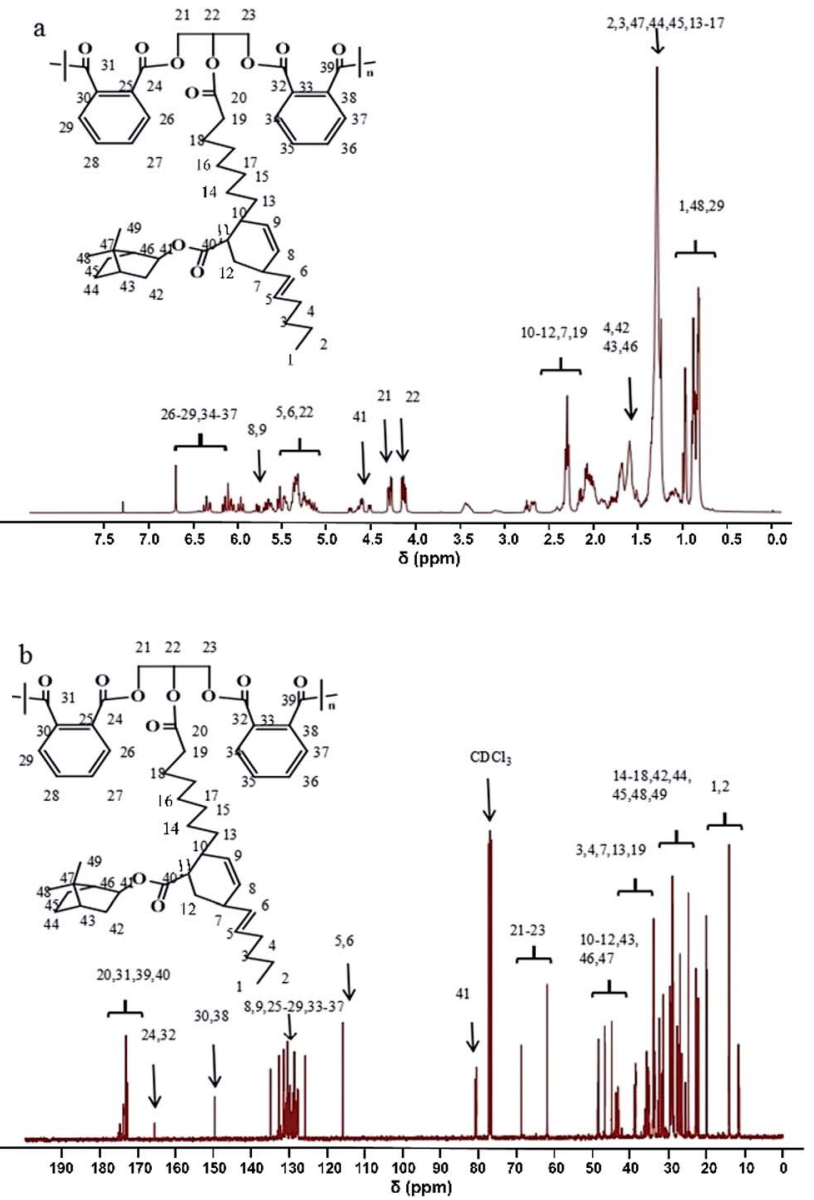

Fig. $2{ }^{1} \mathrm{H}-\mathrm{NMR}(\mathrm{a})$ and ${ }^{13} \mathrm{C}-\mathrm{NMR}(\mathrm{b})$ of tung oil-based acrylated-alkyd resin.

characterized by AFM. Some small, globular-shaped protrusions, like particles, with diameters from nanometer to microns could be identified in the tung oil-based acrylated-alkyd resin with different IBOA content as depicted in the AFM image in Fig. 3b-d. These protrusions can be attributed to the incompatibility between the rigid ring structure of IBOA and the alkane segments of tung oil. Because IBOA and tung oil are covalently bonded together through the Diels-Alder reaction, they cannot demix macroscopically. Therefore, microphase separation of the blocks was observed since IBOA was incorporated into the alkyd resin. Moreover, the surface roughness was increased from 1.02 to $5.26 \mathrm{~nm}$ with an increase in the IBOA content. The low average roughness was the result of the smooth structure. Therefore, as the IBOA mass fraction increased, the nanoparticles aggregated and thus enlarged, resulting in a rougher surface.

\subsection{Thermal stability of the films}

Thermal stability is a very important factor for the properties of the films, and the TGA and DTG curves of the films with different IBOA contents are shown in Fig. 4. There is a threestage thermal degradation in each curve. The first stage of weight loss mainly resulted from evaporation of the high
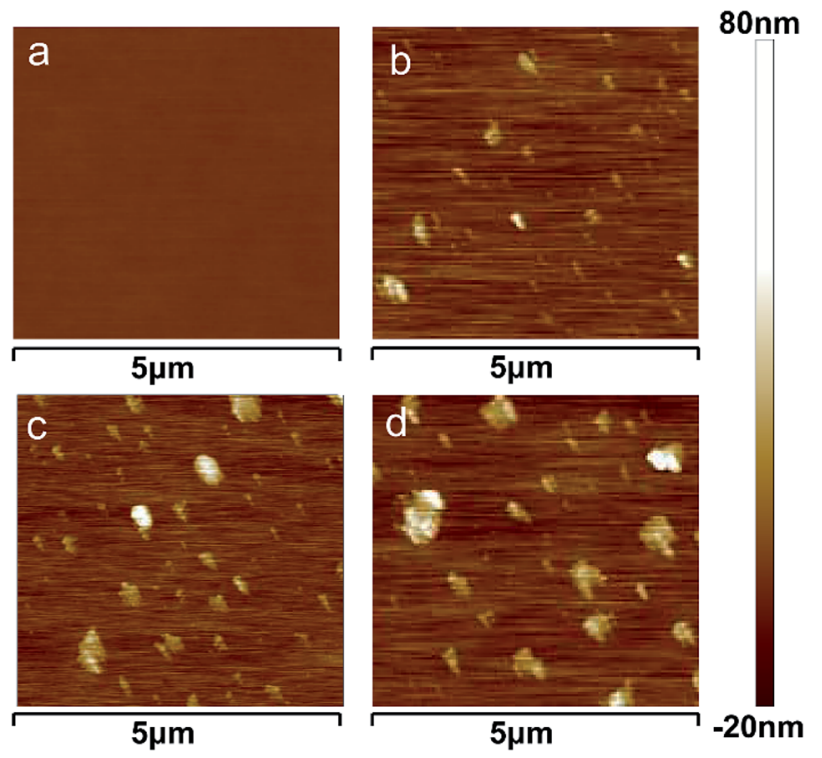

Fig. 3 AFM images of tung oil-based acrylated-alkyd resin with different IBOA content ((a) 0 wt\% IBOA, (b) 10 wt \% IBOA, (c) 20 wt\% IBOA, and (d) 30 wt\% IBOA).

boiling solvent remaining in the films. The prominent second stage was because of the decomposition of the $\mathrm{C}-\mathrm{O}$ and $\mathrm{C}-\mathrm{C}$ linkages, which was the main weight loss stage. The third stage was due to degradation of the char residue. Fig. 4 showed that the temperature at $50 \%$ weight loss increased from $389{ }^{\circ} \mathrm{C}$ to $442{ }^{\circ} \mathrm{C}$ with IBOA content increasing from 0 to $30 \mathrm{wt} \%$. It indicated that the thermal stability of the films was enhanced with the incorporation of IBOA. There were two reasons for this: on the first hand, the Diels-Alder reaction occurred between tung oil and IBOA to form a new, relatively stable six-membered ring, which limited the movement of the polymer segments. On the other hand, the natural rigid six-membered ring structure from IBOA may result in an improvement of the thermal stability. As the IBOA content increased, the number of both natural and generated six-membered rings in the polymeric matrix increased and improved the thermal stability of the films because it restricted the free movement of the alkane chain. The derivative thermogram (DTG) curves (Fig. 4) showed a multiplestep decomposition of tung oil-based acrylated-alkyd resin samples. There was one prominent peak in the DTG curves. The position of the DTG was shifted along with the increase in IBOA content in tung oil-based acrylated-alkyd resin samples. From the TGA results, it can be concluded that modification of the alkyd resin with IBOA significantly improves the thermal stability of the alkyd resin, while no significant changes occur in the degradation process.

\subsection{DSC analysis}

Glass transition is the inherent nature of amorphous polymer materials. The glass-transition temperature $\left(T_{\mathrm{g}}\right)$ of a material characterizes the range of temperatures over which this glass transition occurs. DSC was used to evaluate the glass transition temperature of the films, to study the effect of IBOA content on 

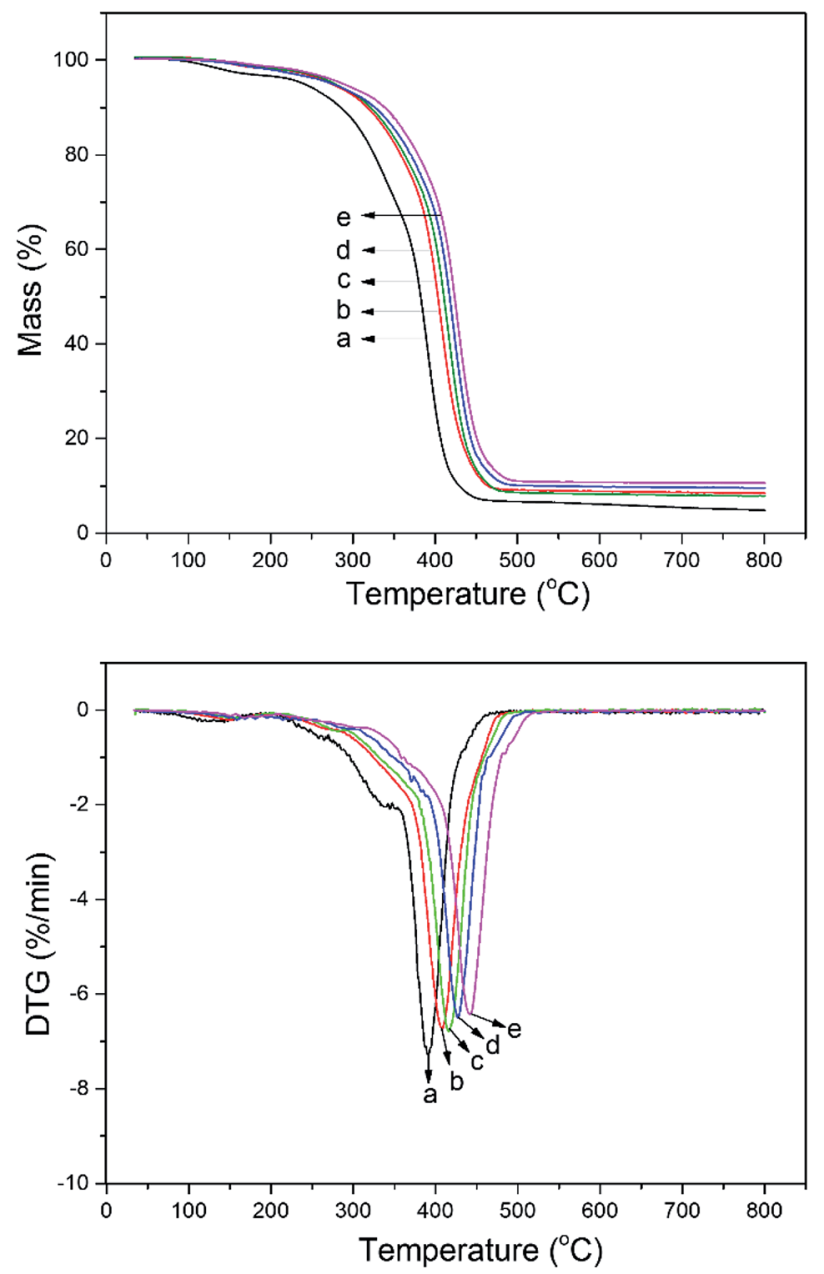

Fig. 4 TG and DTG curves of tung oil-based acrylated-alkyd resin with different IBOA content ((a) 0 wt\% IBOA, (b) 10 wt\% IBOA, (c) 20 wt\% IBOA, (d) 25 wt $\%$ IBOA, and (e) 30 wt\% IBOA).

the thermal stability, and the results are shown Fig. 5. As shown in Fig. 5, the films with IBOA contents of $0,10,20,25$, and 30 wt\% showed a $T_{\mathrm{g}}$ of about $31.6,35.5,37.9,39.2$, and $41.7^{\circ} \mathrm{C}$, respectively. There was an endothermic peak near the glass transition in each curve because of enthalpy relaxation, which is often observed in the $T_{\mathrm{g}}$ region during the heating of glassy materials. ${ }^{28}$ According to the DSC curves, the $T_{\mathrm{g}}$ values of the films increased with increasing IBOA content. It showed that the incorporation of IBOA had a positive effect on the glass transition of the polymer. There is some relationship between $T_{\mathrm{g}}$ and polymer segment flexibility. Generally, the more flexible the polymer chain is, the lower the $T_{\mathrm{g}}$ is. As the number of sixmembered rings in the polymer chain increased with increasing IBOA content, the polymer chain performance was more rigid, and it limited the movement of the polymer segments and caused an increase in $T_{\mathrm{g}}$ accordingly; $;{ }^{16,21}$ this is what led to the increase of $T_{\mathrm{g}}$. On the other hand, this increase may also result from the high cross-linking density associated with the increase of IBOA. ${ }^{27}$ The above reasons caused the $T_{\mathrm{g}}$ value to increase from $31.6{ }^{\circ} \mathrm{C}$ to $41.7^{\circ} \mathrm{C}$.

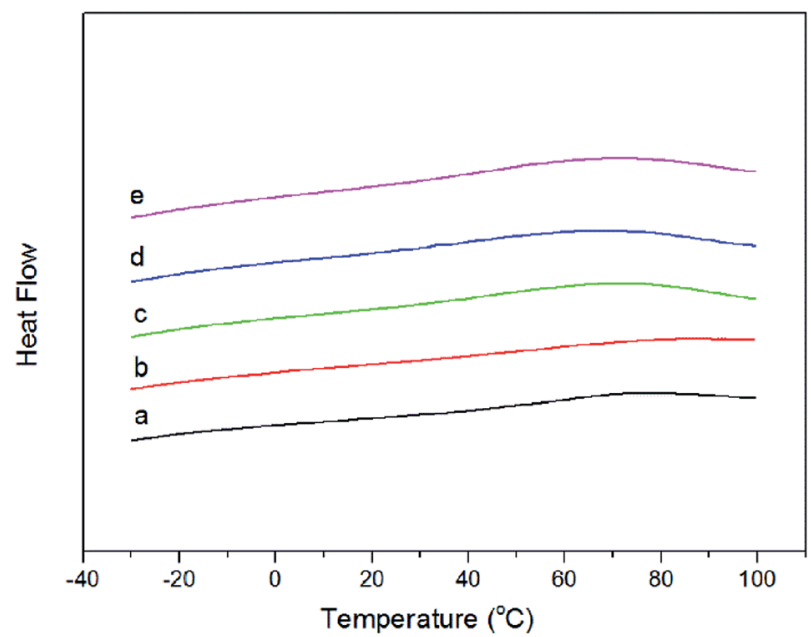

Fig. 5 DSC curves of tung oil-based acrylated-alkyd resin with different IBOA content ((a) 0 wt\% IBOA, (b) 10 wt\% IBOA, (c) 20 wt\% IBOA, (d) $25 w t \%$ IBOA, and (e) $30 w t \%$ IBOA).

\subsection{Physico-chemical properties}

The physico-chemical properties of tung oil-based acrylatedalkyd resin are exhibited in Table 2 . The acid value (17.4$20.3 \mathrm{mg} \mathrm{KOH}$ per g), saponification values (74.1-76.7 mg KOH per g) and low volatile matter (7.94-8.44 Pa s) of alkyd resins support its non-polluting paint and coating applications. ${ }^{1}$ The acid values of the resins varied in the range $17-21 \mathrm{mg} \mathrm{KOH}$ per g. The relatively steady acid values with increasing IBOA enable good water resistance. The viscosity of alkyd resin depends on hydrogen bonding, geometrical configuration and close packing. IBOA can react with the $\alpha$-eleostearic fatty moiety via Diels-Alder reaction, and the viscosity increases along with the increasing proportion of IBOA, which may be caused by more Diels-Alder reactions and higher cross-linking density from IBOA. The hydroxyl values of the tung oil-based acrylatedalkyd resins varied from 74.1 to $76.7 \mathrm{mg} \mathrm{KOH}$ per g; it changed slightly with increased IBOA, which indicates that a threedimensional network formed as a result of crosslinking of tung oil-based acrylated-alkyd chains. In addition, tung oil is a yellow coloured liquid, and therefore the colour of tung oilbased acrylated-alkyd resin is darker, which is presented in Table 2.

Table 2 Physico-chemical properties of tung oil-based acrylatedalkyd resin

IBOA

content Acid value Viscosity Hydroxyl value

$($ wt $\%) \quad(\mathrm{mg} \mathrm{KOH}$ per g) $\quad(\mathrm{Pa} \mathrm{s}) \quad(\mathrm{mg} \mathrm{KOH}$ per g) $\quad$ Color

\begin{tabular}{lllll}
\hline 0 & 17.4 & 7.94 & 74.1 & Dark yellow \\
10 & 18.9 & 8.21 & 74.4 & Dark yellow \\
20 & 20.2 & 8.09 & 76.5 & Dark yellow \\
25 & 19.8 & 8.16 & 75.9 & Dark yellow \\
30 & 20.3 & 8.44 & 76.7 & Dark yellow
\end{tabular}


Table 3 Physical properties of tung oil-based acrylated-alkyd resin

\begin{tabular}{|c|c|c|c|c|c|}
\hline $\begin{array}{l}\text { IBOA content } \\
(\mathrm{wt} \%)\end{array}$ & Pencil hardness & $\begin{array}{l}\text { Water absorption } \\
(\%)\end{array}$ & $\begin{array}{l}\text { Surface roughness } \\
R_{\mathrm{a}}(\mathrm{nm})\end{array}$ & $\begin{array}{l}\text { Tensile strength } \\
\text { at break (MPa) }\end{array}$ & $\begin{array}{l}\text { Elongation at } \\
\text { break (\%) }\end{array}$ \\
\hline 0 & $\mathrm{H}$ & 3.54 & 1.02 & 6.13 & 44.07 \\
\hline 20 & $2 \mathrm{H}$ & 1.06 & 3.92 & 9.28 & 23.95 \\
\hline 25 & $3 \mathrm{H}$ & 0.99 & 4.39 & 10.09 & 20.15 \\
\hline 30 & $3 \mathrm{H}$ & 0.89 & 5.26 & 10.86 & 15.12 \\
\hline
\end{tabular}

\subsection{Physical properties}

The physical properties of cured tung oil-based acrylated-alkyd resins are given in Table 3 . The pencil hardness characteristics of all cured resin films are in the range of $\mathrm{H}$ and $3 \mathrm{H}$ with the increase of IBOA content, which is due to the presence of sixmembered rings in the polymeric matrix from IBOA. The water resistance of the samples is evaluated by water absorption. The difference in the water resistance of different films is showed in Table 3. The water absorption of the films reduced from $3.54 \%$ to $0.89 \%$ with an increase in the IBOA content from 0 to $30 \mathrm{wt} \%$. More hydrophobic structures of natural and generated six-membered rings were produced with increasing IBOA content, which is consistent with TG and DSC analysis, and this resulted in reduction of the water absorption of films. Surface roughness is a component of surface texture. It is quantified by the deviations in the direction of the normal vector of a real surface from its ideal form. It can be seen in Table 3 that with the increase of IBOA content, the surface roughness increased from 1.02 to $5.26 \mathrm{~nm}$. Some small, globular-shaped particles could be identified in tung oil-based acrylated-alkyd resin, as depicted in the AFM image in Fig. 3. Therefore, as the IBOA weight percent increased, the nanoparticles aggregated and thus enlarged, generating a rougher surface. Moreover, superior hydrophobic properties were obtained with a water absorption of $0.89 \%$ when the roughness was $5.26 \mathrm{~nm}$ at an IBOA content of $30 \mathrm{wt} \%$. Therefore, the results are consistent with the idea that the hydrophobic properties also depend on the surface roughness of tung oilbased acrylated-alkyd resin films. ${ }^{29}$

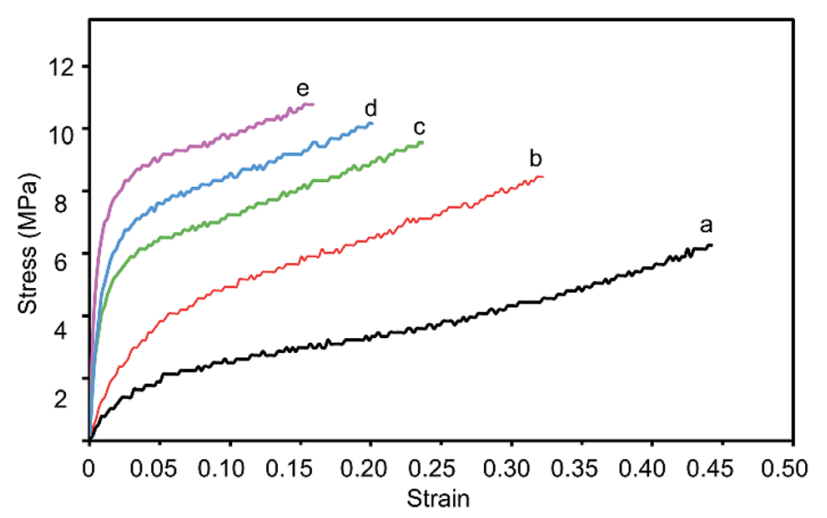

Fig. 6 Stress-strain curves of tung oil-based acrylated-alkyd resin with different IBOA content ((a) 0 wt\% IBOA, (b) 10 wt\% IBOA, (c) 20 wt \% IBOA, (d) 25 wt\% IBOA, and (e) 30 wt\% IBOA).
The effects of IBOA on the mechanical properties of alkyd resin were evaluated, and the stress-strain curves of the films are plotted in Fig. 6 and Table 3. The tensile strength of the tung oilbased acrylated-alkyd resin improved significantly with IBOA. As shown in Fig. 6, all films showed a tough hard plastic behaviour, and the tensile strength at break increased from 8.22 to $10.86 \mathrm{MPa}$ with increasing IBOA content from $10 \%$ to $30 \%$, as shown in Table 3 . The increment of tensile strength of tung oil-based acrylatedalkyd resin can be attributed to the restriction of hard segments on the free movement of soft segments. For the tung oil-based acrylated-alkyd resin, three rigid rings were incorporated into the alkane chain of tung oil by IBOA via the Diels-Alder reaction, which restricted the free movement of the alkane chain. Furthermore, the microphase separation in the alkyd resin because of the incompatibility between the rigid ring and alkane chain is also a factor for the improvement of tensile strength. The elongation at break reduced from $44.07 \%$ to $15.12 \%$ with increasing IBOA content from $10 \%$ to $30 \%$, which is attributed to the restriction of the soft segment as well. As a hard monomer, IBOA can improve the tensile strength of films because its rigid six-membered ring structure was able to restrict segmental motions.

\section{Conclusion}

Tung oil-based acrylated-alkyd resins were successfully synthesized with various proportions of IBOA by three stages comprising alcoholysis, polyesterification and Diels-Alder addition. It showed that the induction of IBOA played an important role in the enhancement of the properties of the resin due to the presence of six-membered rings in the polymeric matrix from IBOA, which restricted the free movement of the alkane chain. As the IBOA content increased, the thermal stability, water resistance, pencil hardness and mechanical properties of the alkyd resins were improved significantly. The thermal stability and tensile strength were increased to $442{ }^{\circ} \mathrm{C}$ and $10.86 \mathrm{MPa}$, respectively. Moreover, the water absorption was reduced to $0.89 \%$. The research revealed that tung oil can be utilized as a potential source of raw material for surface coating applications.

\section{Acknowledgements}

The authors gratefully acknowledge the project supported by the National R\&D projects "Key Technology of Green Processing and Efficient Utilization on Oleoresin" (Grant No. 2016YFD0600804), and the National Natural Science Foundation of China (Grants No. 31600462). 


\section{Notes and references}

1 P. P. Chiplunkar and A. P. Pratap, Prog. Org. Coat., 2016, 93, 61-67.

2 E. E. Essien, S. A. Umoren and E. E. Effiong, Res. Chem. Intermed., 2016, 42, 2177-2189.

3 P. Gogoi, D. Das, S. Sharma and S. K. Dolui, J. Renewable Mater., 2015, 3, 151-159.

4 P. R. Hondred, C. Autori and M. R. Kessler, Macromol. Mater. Eng., 2014, 299, 1062-1069.

5 A. Jianprasert, P. Monvisade and M. Yamaguchi, in 2015 the 4th International Conference on Material Science And Engineering Technology, ed. J. Zhou and O. Adiguzel, 2015, vol. 30 .

6 S. A. Madbouly, K. W. Liu, Y. Xia and M. R. Kessler, RSC Adv., 2014, 4, 6710-6718.

7 H. Izadi-Vasafi, G. M. M. Sadeghi, A. Babaei and F. Ghayoumi, Fibers Polym., 2016, 17, 311-323.

8 C. G. Liu, Y. Dai, C. S. Wang, H. F. Xie, Y. H. Zhou, X. Y. Lin and L. Y. Zhang, Ind. Crops Prod., 2013, 43, 677-683.

9 G. Z. Ma, T. Zhang, J. B. Wu, C. Y. Hou, L. X. Ling and B. J. Wang, J. Appl. Polym. Sci., 2013, 130, 1700-1706.

10 M. A. Mosiewicki, U. Casado, N. E. Marcovich and M. I. Aranguren, Polym. Eng. Sci., 2009, 49, 685-692.

11 E. F. Assanvo, P. Gogoi, S. K. Dolui and S. D. Baruah, Ind. Crops Prod., 2015, 65, 293-302.

12 P. Gogoi, M. Boruah, S. Sharma and S. K. Dolui, ACS Sustainable Chem. Eng., 2015, 3, 261-268.

13 T. S. Radoman, J. V. Džunuzović, K. T. Trifković, T. Palija, A. D. Marinković, B. Bugarski and E. S. Dzunuzovic, Express Polym. Lett., 2015, 9, 916-931.

14 M. D. Soucek and R. R. Salata, in Encyclopedia of Polymeric Nanomaterials, ed. S. Kobayashi and K. Müllen, Springer
Berlin Heidelberg, Berlin, Heidelberg, 2015, pp. 12-17, DOI: 10.1007/978-3-642-29648-2_278.

15 M. Tahmaz, I. Acar and G. Güçlü, Res. Chem. Intermed., 2015, 41, 27-42.

16 Y. Xia and R. C. Larock, Green Chem., 2010, 12, 1893-1909.

17 N. Thanamongkollit, K. R. Miller and M. D. Soucek, Prog. Org. Coat., 2012, 73, 425-434.

18 F. Li and R. C. Larock, Biomacromolecules, 2003, 4, 10181025.

19 N. Thanamongkollit and M. D. Soucek, Prog. Org. Coat., 2012, 73, 382-391.

20 D. L. Trumbo and B. E. Mote, J. Appl. Polym. Sci., 2001, 80, 2369-2375.

21 K. Wutticharoenwong, J. Dziczkowski and M. D. Soucek, Prog. Org. Coat., 2012, 73, 283-290.

22 D. Khandelwal, S. Hooda, A. S. Brar and R. Shankar, J. Mol. Struct., 2011, 1004, 121-130.

23 M. Shin, Y. Lee, M. Rahman and H. Kim, Polymer, 2013, 54, 4873-4882.

24 C.-W. Lo, D. Zhu and H. Jiang, Soft Matter, 2011, 7, 56045609.

25 C.-W. Peng, K.-C. Chang, C.-J. Weng, M.-C. Lai, C.-H. Hsu, S.-C. Hsu, S.-Y. Li, Y. Wei and J.-M. Yeh, Polym. Chem., 2013, 4, 926-932.

26 P. M. Spasojevic, V. V. Panic, J. V. Dzunuzovic, A. D. Marinkovic, A. J. J. Woortman, K. Loos and I. G. Popovic, RSC Adv., 2015, 5, 62273-62283.

27 Y. Huang, G. Ye and J. Yang, Prog. Org. Coat., 2015, 78, 28-34. 28 Q. Ge, H. L. Wang, Y. She, S. W. Jiang, M. Y. Cao, L. F. Zhai and S. T. Jiang, J. Appl. Polym. Sci., 2015, 132, 41608.

29 X. Huang, A. Wang, X. Xu, H. Liu and S. Shang, ACS Sustainable Chem. Eng., 2017, 5, 1619-1627. 